\title{
BCL-2, topoisomerase II $\alpha$, microvessel density and prognosis of early advanced breast cancer patients after adjuvant anthracycline-based chemotherapy
}

\author{
Beata Biesaga $\cdot$ Joanna Niemiec $\cdot$ Marek Ziobro
}

Received: 25 April 2014 / Accepted: 29 June 2014 / Published online: 9 July 2014

(C) The Author(s) 2014. This article is published with open access at Springerlink.com

\begin{abstract}
Purpose The aim of this retrospective study was to investigate the effect of B cell lymphoma 2 (BCL-2) expression on disease-free survival (DFS) in 172 early breast cancer (BC) patients treated with anthracycline-based adjuvant chemotherapy. We have reanalysed follow-up data in these patient groups, and therefore, the relation between DFS and other tumour biological features [expression of oestrogen $(\mathrm{ER})$ and progesterone $(\mathrm{PgR})$ receptors, cytokeratin 5/6 (CK5/6), HER2, topoisomerase II $\alpha$ (TOPOII $\alpha$ ), Ki-67, P53 and microvessel density (MVD)] studied previously (Biesaga et al. in Breast 20(4):338-350, 2011, doi:10.1016/j.breast.2011.03.002, Pathol Oncol Res 18(4): 949-960, 2012, doi:10.1007/s12253-012-9525-9) was also investigated.

Method Tumour biological features were assessed immunohistochemically on paraffin-embedded sections obtained before treatment from 172 women with BC in stage T1-T2, N1-N2, M0.

Results In univariate analysis, longer DFS was found for patients having tumours with BCL-2 positivity $(P=0.005)$, low grade $(P=0.001), \mathrm{ER}(P=0.017)$ and $\operatorname{PgR}(P=0.045)$ positivity, CK5/6 negativity $(P=0.021)$, low TOPOII $\alpha$ expression $(P=0.003)$ and high MVD $(P=0.000)$. In multivariate analysis, BCL-2, TOPOII $\alpha$ and MVD were independent parameters indicating patient prognosis. All patients $(n=18)$ characterized by tumour
\end{abstract}

\footnotetext{
B. Biesaga $(\bowtie) \cdot$ J. Niemiec

Department of Applied Radiobiology, Centre of Oncology, ul. Garncarska 11,31-115 Kraków, Poland

e-mail: z5biesag@cyfronet.pl
}

M. Ziobro

Department of Medical Oncology, Centre of Oncology,

ul. Garncarska 11, 31-115 Kraków, Poland
BCL-2 positivity, low TOPOII $\alpha$ expression and high MVD survived 80 months without any evidence of cancer disease, whereas DFS for all other patients was significantly $(P=0.022)$ lower $(76.5 \%)$.

Conclusion Combination of three parameters: BCL-2 positivity, low topoisomerase II $\alpha$ expression and high MVD, allows to identify subgroup of BC patients with very good prognosis after adjuvant anthracycline-based chemotherapy.

Keywords Early breast cancer patients - Anthracyclines · Potential prognostic factors

\section{Introduction}

Adjuvant systemic therapy of patients with early advanced breast cancer (BC) significantly reduces recurrence risk and overall mortality. Anthracyclines (ATC) are the most commonly used drugs in the adjuvant chemotherapy (CT) of breast cancer. The last meta-analysis of Early Breast Cancer Trialists' Collaborative Group demonstrated that regimens based on higher dosages of ATC are associated with around $4 \%$ reduction of recurrence rate and overall mortality as compared with cyclophosphamide, methotrexate and fluorouracil scheme (CMF) (EBCTCG et al. 2012). There is a possibility to improve treatment outcome by more differentiated therapy, tailored to the biological characteristics of the tumour cells. For this purpose, it is necessary to undertake translational researches, consisting in the development of biological prognostic and predictive factors for adjuvant chemotherapy based on ATC. Today, there is no reliable prognostic factor which allows discrimination between patients who will benefit from adjuvant ATC treatment and those who will not. In our previous papers, in the 
Table 1 Studies on BCL-2 prognostic potential for adjuvant anthracycline-based chemotherapy

\begin{tabular}{|c|c|c|c|c|}
\hline References & $N$ & Adjuvant chemotherapy type & $\begin{array}{l}\text { Cut-off point for BCL-2 } \\
\text { immuno-positivity/overexpression }\end{array}$ & BCL-2 prognostic significance \\
\hline van Slooten et al. (1996) & 423 & $\begin{array}{l}202 \text { pts: no adjuvant CT } \\
221 \text { pts: FAC }\end{array}$ & $\begin{array}{l}>75 \% \text { of cells with moderate or } \\
\text { strong intensity }\end{array}$ & $\begin{array}{l}\text { BCL-2 positivity: better DFS, lack } \\
\text { of significance in multivariate } \\
\text { analysis }\end{array}$ \\
\hline Mottolese et al. (2000) & 157 & $\begin{array}{l}4 \text { cycles of EC or } \\
4 \text { cycles of EC + lonidamine or } \\
4 \text { cycles of EC + G-CSF or } \\
4 \text { cycles of EC + lonid- } \\
\text { amine }+ \text { G-CSF }\end{array}$ & $>20 \%$ of stained cells & $\begin{array}{l}\text { In the entire cohort: no significance } \\
\text { in lobular carcinomas: } \\
\text { BCL-2 positivity: worse OS and } \\
\text { DFS }\end{array}$ \\
\hline Yang et al. (2003) & 147 & All pts: FEC & & $\begin{array}{l}\text { BCL-2 positivity: better OS and } \\
\text { DFS confirmed in multivariate } \\
\text { analysis }\end{array}$ \\
\hline Kröger et al. (2006) & 157 & $\begin{array}{l}78 \text { pts: } 3 \text { cycles of CMF } \\
79 \text { pts: } 4 \text { cycles of } \\
\text { EC } \rightarrow \text { CTM } \rightarrow \text { stem } \\
\text { cell support }\end{array}$ & $>0 \%$ of stained cells & $\begin{array}{l}\text { BCL-2 positivity: better EFS, con- } \\
\text { firmed in multivariate analysis }\end{array}$ \\
\hline Lee et al. (2007) & 151 & $\mathrm{AC} \rightarrow \mathrm{T}$ & $>0 \%$ of stained cells & $\begin{array}{l}\text { BCL-2 positivity: better OS and } \\
\text { DFS confirmed in multivariate } \\
\text { analysis }\end{array}$ \\
\hline Dumontet et al. (2010) & 1,342 & $\begin{array}{l}663 \text { pts: FAC } \\
679 \text { pts: TAC }\end{array}$ & $>70 \%$ of stained cells & $\begin{array}{l}\text { BCL-2 positivity: better OS and } \\
\text { DFS, lack of significance in } \\
\text { multivariate analysis }\end{array}$ \\
\hline Abdel-Fatah et al. (2010) & 1,235 & $\begin{array}{l}377 \text { pts: no adjuvant treatment } \\
382 \text { pts: hormonal therapy } \\
182 \text { pts: CMF } \\
32 \text { pts: CMF + hormonal therapy } \\
245 \text { pts: anthracyclines }\end{array}$ & $>10 \%$ of stained cells & $\begin{array}{l}\text { The entire patient cohort and } \\
\text { separately patients treated with } \\
\text { anthracyclines: } \\
\text { BCL-2 positivity: better DFS and } \\
\text { BCSS confirmed in multivariate } \\
\text { analysis }\end{array}$ \\
\hline Kim et al. (2010) & 100 & $\begin{array}{l}24 \text { pts: no adjuvant treatment } \\
30 \text { pts: CMF } \\
27 \text { pts: doxorubicin containing CT } \\
3 \text { pts: others chemotherapy } \\
16 \text { pts: hormonal therapy only }\end{array}$ & $>10 \%$ of stained cells & No significance \\
\hline
\end{tabular}

pts patients, $C T$ chemotherapy, FAC 5-fluorouracil and doxorubicin and cyclophosphamide, DFS disease-free survival, EC epirubicin and cyclophosphamide, $O S$ overall survival, $C M F$ cyclophosphamide and methotrexate and 5-fluorouracil, $C T M$ cyclophosphamide and tiotepa and mitoxantrone, EFS event free survival, $A C$ doxorubicin and cyclophosphamide, $T$ paclitaxel, $T A C$ docetaxel and doxorubicin and cyclophosphamide, $B C S S$ breast cancer-specific survival

group of 167 patients with breast cancers in clinical stage T1-T2, N1-N2, M0, treated with ATC in adjuvant setting, we have shown prognostic potential of topoisomerase II $\alpha$ (TOPOII $\alpha$ ) expression (Biesaga et al. 2011) and tumour microvessel density (MVD) (Biesaga et al. 2012). However, chemotherapeutic agents such as ATC, irrespective of their intracellular target, act through induction of apoptosis in cancer cells. Therefore, alterations in the regulatory mechanism of apoptosis are responsible not only for cancer progression, but also for different response to treatment.

Antiapoptotic protein B cell lymphoma 2 (BCL-2) is one of the most extensively studied apoptosis regulators in translational studies, but its role in ATC resistance/sensitivity is unclear. There are a few reports (see Table 1), in which prognostic potential of BCL-2 expression was investigated in the breast cancer patient groups consisting of subgroups of women treated with ATC in adjuvant setting, although in all these studies, expect one (Abdel-Fatah et al. 2010) not analysed separately. In these studies, contradictory results were obtained. Moreover, in two meta-analyses, performed to investigate BCL-2 prognostic potential, opposite results were reported. Callagy et al. (2006) have shown positive prognostic significance of BCL-2 overexpression, whereas Yang et al. (2013) have found significant relation between BCL-2 negativity and good prognosis. These contradictions may be the effect of at least four causes: (1) other than antiapoptotic function of BCL-2 [the influence on cell cycle progression (Zinkel et al. 2006; Pietenpol et al. 1994)], (2) regulation of BCL-2 expression through oestrogen pathway (Perillo et al. 2000), (3) lack of homogeneity in patient group studied (according to clinical stage and adjuvant treatment type) and (4) differences in IHC 
procedure and cut-off points used to identified BCL-2 positivity and negativity (Table 1). Thus, there is still a need to evaluate the prognostic role of BCL-2 in BC patients.

The aim of the present study was to evaluate the prognostic significance of BCL-2 expression in the group of 172 women with breast cancer in clinical stage T1-T2, N1-N2, M0, treated with ATC in adjuvant settings. For this purpose, we assessed the correlation between this parameter and patient disease-free survival (DFS). Because in the present patient group we reanalysed follow-up data, we decided to assess once again the influence of all clinical (patients' age tumour size, lymph node metastases, grade) and biological features (expression of steroid hormone receptors, cytokeratin 5/6 (CK5/6), HER2, TOPOII $\alpha$, Ki-67, P53 and MVD), which were previously studied (Biesaga et al. 2011, 2012) on DFS of breast cancer patients.

\section{Materials and methods}

\section{Patients}

This study was performed in the group of 172 patients with breast cancer who met the following criteria: (1) invasive ductal breast cancer in clinical stage T1-T2, N1-N2, M0, (2) radical surgery (mastectomy or breast conserving therapy), (3) adjuvant anthracycline-based chemotherapy (according to two regimes: FAC-5-fluorouracil, doxorubicin, cyclophosphamide or AC-doxorubicin, cyclophosphamide). All other details concerning this patient group were presented previously (Biesaga et al. 2011, 2012).

The study has been approved by the Ethics Committee at the Centre of Oncology, Krakow, Poland (date of issue 14.02.2006).

\section{Tumour samples}

Formalin-fixed, paraffin-embedded tissue blocks were obtained from each patient, and serial $4-\mu \mathrm{m}$ sections were processed for application of the immunohistochemistry (IHC).

\section{Immunohistochemistry}

In order to assess BCL-2 expression, IHC staining was performed on 5 - $\mu \mathrm{m}$-thick sections from routinely fixed paraffin-embedded blocks. To unmask antigen, the deparaffinized (trough xylene series) and rehydrated sections (in decreasing concentrations of ethanol) were incubated for $50 \mathrm{~min}$. in TRS (pH 6.1, DAKOCytomation, Glostrup, Denmark) preheated to $96{ }^{\circ} \mathrm{C}$. Endogenous peroxidases were quenched by $30 \mathrm{~min}$. incubation in $3 \%$ hydrogen peroxide in $70 \%$ methanol. Whole night incubation with diluted primary (1:40) antibody (Monoclonal Mouse AntiHuman, BCL-2 Oncoprotein, Clone 124, DAKOCytomation, Glostrup, Denmark) at $4{ }^{\circ} \mathrm{C}$ in humidity chamber was carried out (Table 2). The antigen-primary antibody immunoreaction was detected by BrightVision Poly- HRP-Anti $\mathrm{Ms} / \mathrm{Rb} / \mathrm{Rt} \operatorname{IgG}$ (ImmunoLogic, Duiven, the Netherlands). For this purpose, after three times washing in TBS-T, the slides were incubated at room temperature (RT) with postantibody blocking for $15 \mathrm{~min}$ and with poly-HRP-goat anti-mouse/rabbit IgG for $30 \mathrm{~min}$. Peroxidase was visualized using $0.01 \%$ 3.3-diaminobenzidine tetrahydrochloride (DAB) and $0.015 \%$ hydrogen peroxide. The slides were counterstained with Mayer's haematoxylin. Tumour specimen with known strong BCL-2 expression added to each series of staining was treated as positive control. For negative control, TBS was substituted for the primary antibody.

Samples were analysed using Olympus microscope at $400 \times$ magnification. BCL-2 expression was scored according to classification presented by Treré et al. (2007), because based on it, they found significant relation between BCL-2 expression assessed by IHC and its mRNA level. According to this scale, three classes of BCL-2 expression were identified: 0 -lack of immunostaining (no BCL-2 expression), 1-heterogeneous staining within tumour area, regardless of the intensity (BCL-2 expression) and 2-intense staining in all tumour cells (BCL-2 overexpression) (Fig. 1a-c).

All details regarding immunohistochemical analysis of steroid hormone receptors, CK5/6, HER2, TOPOII $\alpha$, Ki-67, P53 expression and MVD have been previously described (Biesaga et al. 2011, 2012) and in the present paper summarized in Table 2.

Breast cancer immunophenotypes were identified on the basis of ER, PgR, HER2 and Ki-67 labelling index (Ki-67LI) according to St. Gallen Expert Consensus (Goldhirsch et al. 2013): luminal A-like (LA): ER and PgR positive, HER2 negative and Ki-67 "low" (in the present cohort $\leq 19.7 \%$ ), luminal B HER2 ${ }^{-}$(LBHER2 ${ }^{-}$): ER positive, HER2 negative and at least one of: Ki-67 "high" (in the present cohort $>19.7 \%$ ) or PgR negative, luminal B HER2 $^{+}\left(\right.$LBHER $\left.^{+}\right)$: ER positive, HER2 overexpressed or amplified, any Ki-67, any PgR, HER2 ${ }^{+}$: HER2 overexpressed or amplified, ER and PgR absent, triple negative (TN): ER and PgR absent, HER2 negative.

\section{Statistical methods}

All statistical analyses were carried out using Statistica v.10.0 program (StatSoft, USA). Descriptive statistics were used to determine mean and median values of continuous variables and standard errors of means (SE). The significance of differences in continuous variables between groups was assessed on the basis of Mann-Witney $U$ test. Independence of 
Table 2 Details of immunohistochemistry staining

\begin{tabular}{|c|c|c|c|c|c|}
\hline Antigen & Clone & Source & Dilution & $\begin{array}{l}\text { Detection } \\
\text { system }\end{array}$ & Criteria for IHC positivity/overexpression \\
\hline ER & $6 \mathrm{~F} 11$ & Novocastra $^{a}$ & $1: 50$ & EnVision $^{\mathrm{b}}$ & $>10 \%$ of tumour immunopositive cells \\
\hline $\operatorname{PgR}$ & $1 \mathrm{~A} 6$ & Novocastra $^{a}$ & $1: 50$ & EnVision $^{\mathrm{b}}$ & $>10 \%$ of tumour immunopositive cells \\
\hline HER2 & - & $\mathrm{DAKO}^{\mathrm{b}}$ & $1: 250$ & EnVision $^{\mathrm{b}}$ & $\begin{array}{l}\text { Strong complete uniform membrane staining in }>30 \% \text { of tumour cells } \\
\text { or complete membrane staining in }>10 \% \text { of tumour cells confirmed } \\
\text { by FISH }\end{array}$ \\
\hline CK 5/6 & D5/16 B4 & $\mathrm{DAKO}^{\mathrm{b}}$ & $1: 50$ & EnVision $^{\mathrm{b}}$ & $>10 \%$ of tumour immunopositive cells \\
\hline TOPOII $\alpha$ & $3 \mathrm{~F} 6$ & Novocastra $^{a}$ & $1: 30$ & EnVision $^{\mathrm{b}}$ & $\begin{array}{l}\text { TOPOII } \alpha \text { labelling index (TOPOII } \alpha \mathrm{LI} \text { - the percentage of TOPOII } \alpha \\
\text { immunopositive tumour cells) }>11.9 \% \text { (median value) }\end{array}$ \\
\hline $\mathrm{Ki}-67$ & MIB-1 & $\mathrm{DAKO}^{\mathrm{b}}$ & $1: 75$ & EnVision $^{\mathrm{b}}$ & $\begin{array}{l}\text { Ki-67 labelling index }(\mathrm{Ki}-67 \mathrm{LI}-\text { the percentage of Ki-67 immunoposi- } \\
\text { tive tumour cells) }>19.7 \% \text { (median value) }\end{array}$ \\
\hline CD34 & QBEnd 10 & $\mathrm{DAKO}^{\mathrm{b}}$ & $1: 50$ & EnVision $^{\mathrm{b}}$ & $\begin{array}{l}\text { High microvessel density (MVD_mean number of microvessels per } \\
\mathrm{mm}^{2} \text { of tumour tissue) }>210.0 \text { vessels } / \mathrm{mm}^{2} \text { (cut-off point found by } \\
\text { minimal } P \text { value method) }\end{array}$ \\
\hline P53 & NCL-P53-1801 & Novocastra $^{a}$ & $1: 40$ & EnVision $^{\mathrm{b}}$ & $\begin{array}{l}\text { P53 labelling (index (P53LI-the percentage of P53 immunopositive } \\
\text { tumour cells) }>10.0 \%\end{array}$ \\
\hline BCL-2 & 124 & $\mathrm{DAKO}^{\mathrm{b}}$ & $1: 40$ & \multicolumn{2}{|c|}{$\begin{array}{c}\text { BrightVision }{ }^{\mathrm{c}} \text { Intense staining in all tumour cells (class } 2 \text { ) or heterogeneous staining } \\
\text { within tumour area, regardless of the intensity (class } 1 \text { ) }\end{array}$} \\
\hline
\end{tabular}

$I H C$ immunohistochemistry, $E R$ oestrogen receptor, $P g R$ progesterone receptor, $H E R 2$ human epidermal growth factor receptor 2, FISH fluorescence in situ hybridization; $C K 5 / 6$ cytokeratin 5/6, TOPOII $\alpha$ topoisomerase II $\alpha$

${ }^{a}$ Laica Biosystems Newcastle Ltd, Newcastle, UK

b DakoCytomation Denmark A/S, Glostrup, Denmark

c ImmunoLogic, Duiven, the Netherlands

Fig. 1 Representative images of BCL-2 immunohistochemical staining in breast cancer tissue and correlation between BCL-2 immunoexpression and other biological features studied. a Negative BCL-2 staining (class 0 -no BCL-2 expression). b Heterogeneous BCL-2 immunostaining within tumour area (class 1-BCL-2 expression). c Intense BCL-2 staining in all tumour cells (class $2-\mathrm{BCL}-2$ overexpression), $\times 200 \mathrm{mag}-$ nification. BCL-2 overexpression is correlated with $\mathbf{d}$ low proliferation rate assessed by Ki-67 labelling index (Ki-67LI), e low P53 level expressed as P53 labelling index (P53LI) (Kruskal-Wallis test)

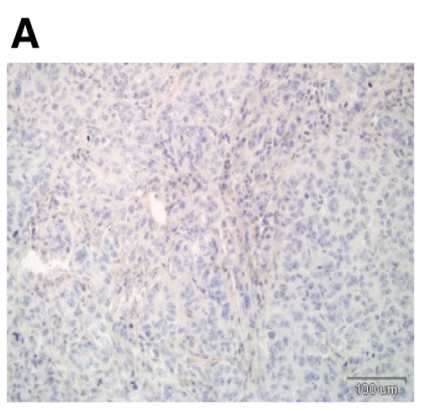

B

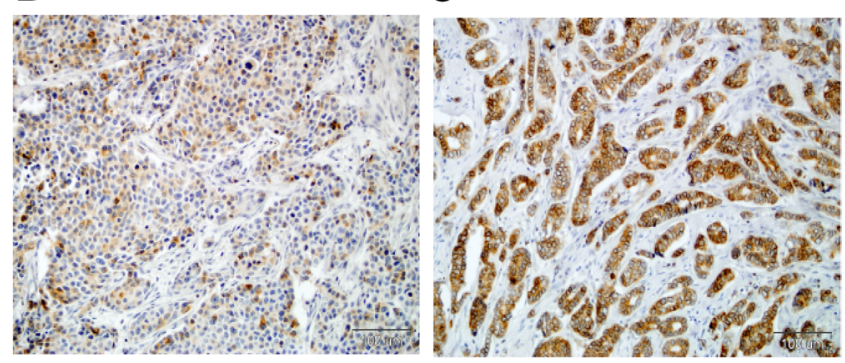

D

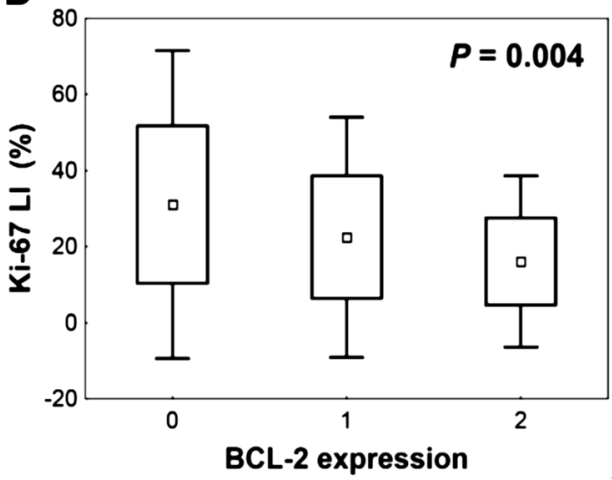

E

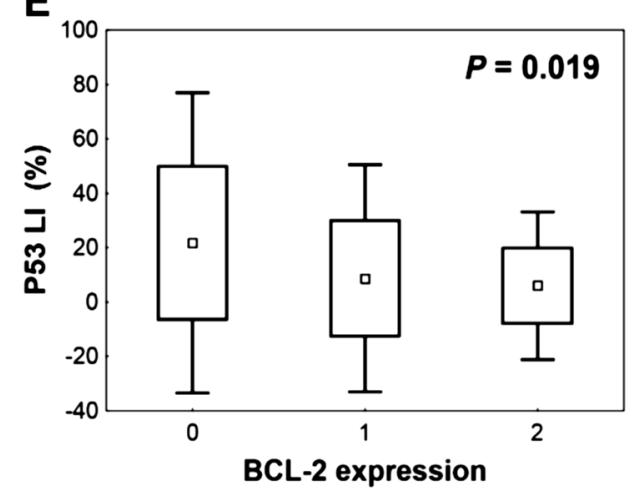

categorical variables expressed in a cross-tab was analysed by Pearson's chi-square test. Cumulative DFS probabilities were estimated using the Kaplan-Meier method, and the significance of differences between survival rates was calculated by the log-rank test. Multivariate analysis was carried out using the Cox proportional hazards model, providing an estimate of the hazard ratio (HR) and a $95 \%$ confidence interval $(95 \%$ CI). $P$ value $<0.05$ was considered to be significant. 


\section{Results}

Patients

A 172 patients with invasive ductal breast cancer were analysed (Table 3). Women aged from 32 to 78 years (with mean and median values 52.8 years \pm 0.67 and 53 years, respectively). Among these, $54.7 \%$ were in clinical stage T1N1, $23.3 \%$ in stage T1N2, $18.0 \%$ in T2N1 and $4.0 \%$ in $\mathrm{T} 2 \mathrm{~N} 2$.

Most of the patients $(89.0 \%)$ were subjected to mastectomy and $11 \%$ underwent breast conserving surgery. All women received adjuvant anthracycline-based chemotherapy according to two regimes: six or four cycles of AC (59.9\% of patients) or six or four cycles of FAC $(40.1 \%$ of patients). The patients were assigned to these two regimes because in the Centre of Oncology, Krakow Branch, the period of time between 2001 and 2005, when patients were recruited for the study, was transition time in the use of FAC instead of AC for adjuvant anthracycline-based chemotherapy. Due to positive lymph nodes, all patients underwent locoregional radiotherapy (45 Gy/2 Gy/day + boost or $50 \mathrm{~Gy} / 2 \mathrm{~Gy} / \mathrm{day}$ ) as soon as possible after last chemotherapy course. All women with ER or PgR positivity $(77.9 \%)$ were treated with tamoxifen for 5 years. Women included in the study did not receive trastuzumab, because in Poland, trastuzumab has been used and reimbursed by the National Health Fund for the adjuvant treatment since 2007.

All data regarding treatment outcome in this patient group were reanalysed in June 2012. In contrast to our earlier analyses (Biesaga et al. 2011, 2012) in which we obtained data for 167 patients, at present follow-up was available for 171 patients, one patient is still lost from follow-up. The mean and median length of follow-up were 61.8 months \pm 1.9 (SE) and 69 months, respectively, (range 1-126 months). Tumour progression (locoregional recurrence, distant recurrence or second malignancy) was observed in 35 patients (20.5\%), after 1-70 months (mean and median values, respectively, 24.8 months \pm 2.7 and 24.0 months) after surgery.

BCL-2 expression, apoptosis level and correlations with clinicopathological features and other immunohistochemical markers

Due to accessibility of material in paraffin blocks in this series, the evaluation of BCL-2 expression was possible for $141(82.0 \%)$ out of 172 patients. According to BCL-2 expression, 38/141 (27.0\%) were classified as 0 (no expression), 70/141 (49.6\%) as 1 (BCL-2 expression) and $33 / 141(23.4 \%)$ as 2 (BCL-2 overexpression) (Table 3). BCL-2 overexpression was significantly related to lower tumour grades $(P=0.001)$, positive hormonal receptors status $(P=0.000)$ and CK5/6 negativity $(P=0.015)$. The significantly higher percentage of tumours overexpressing BCL-2 was also found in LA and LB than in HER2 ${ }^{+}$and TN cancer immunophenotypes, identified on the basis of ER, PgR, HER2 and Ki-67 expression according to St. Gallen International Expert Consensus on The Primary Therapy of Early Breast Cancer 2013 (Goldhirsch et al. 2013).

BCL-2 expression status significantly correlates with Ki-67LI $(P=0.038)$ and P53 labelling index (P53LI) $(P=0.014)$, both analysed as categorical variables. Ki67LI was categorized using median value $(19.7 \%)$. In case of P53LI, we decided, similar to other authors (MalamouMitsi et al. 2006; Mottolese et al. 2000), to accept the threshold for the P53 positivity at the level of $10 \%$. The percentage of BCL-2 overexpressed tumours was significantly higher in lower proliferating cancers with P53 negativity. Similar relations between BCL-2 expression and Ki67LI or P53LI were also observed, if these two variables were analysed as continuous variables (Fig. 1d, e).

There was also a tendency suggesting associations between BCL-2 expression and patient age $(P=0.092)$ or HER2 status $(P=0.084)$; however, these relations did not reach statistical significance.

\section{Univariate survival analysis}

In the present patient cohort, the DFS was $78.8 \%$. Univariate analysis showed the highest DFS (87.9\%) for women having tumours with BCL-2 overexpression (class 2), while the lowest $(64.9 \%)$ for those with BCL-2-negative cancers (class 0) (Table 4). Patients with BCL-2 expression in class 1 were characterized by intermediate DFS $(84.3 \%)$. The differences in DFS according to BCL-2 expression were significant $(P=0.005)$.

The significant differences in DFS according to BCL-2 expression classes were more apparent in the subgroup of younger patients $(P=0.0140)$, with T1 $(P=0.032)$, N1 $(P=0.033)$ tumours, carcinomas characterized by negativity of CK5/6 $(P=0.043)$, HER2 $(P=0.019)$ and P53 $(P=0.037)$, low MVD $(P=0.013)$ and only for patients with cancers having TN immunophenotype. In TN subgroup, women with BCL-2 immunopositive (classes $1+2$ ) tumours were characterized by $85.7 \%$ of DFS, whereas those without BCL-2 expression by $38.5 \%$ of DFS. This difference was statistically significant $(P=0.048)$.

Since we have updated follow-up data, in the present analysis, we also re-examined the relation between DFS and previously evaluated biological features of tumours studied (Biesaga et al. 2011, 2012). For this analysis, in case of three continuous variables: Ki-67LI, TOPOII $\alpha$ LI and MVD, we checked the level of cut-off point by minimum $P$ value method from log-rank test. For Ki-67LI 
Table 3 Clinical and biological features of breast cancer patients stratifying according to BCL-2 expression
HER2 human epidermal growth factor receptor 2, TOPOII $\alpha L I$ topoisomerase II $\alpha$ labelling index, $K i-67 L I \mathrm{Ki}-67$ labelling index, $M V D$ microvessel density, P53LI P53 labelling index, $L A$ luminal $\mathrm{A}, L B$ luminal $\mathrm{B}, T N$ triple negative

1 Column percentage

* Row percentage

${ }^{\text {a }} P$ values are from Pearson's $\chi^{2}$ test

b Mean value

c Median values

d Cut-off point from minimal $P$ value method

${ }^{\mathrm{e}}$ Immunophenotypes indicated on the basis of ER, PgR, HER2 and $\mathrm{Ki}-67$ expression according to St. Gallen International Expert Consensus on The Primary Therapy of Early Breast Cancer 2013 (Goldhirsch et al. 2013)

\begin{tabular}{|c|c|c|c|c|c|}
\hline & \multicolumn{5}{|c|}{ BCL-2 expression } \\
\hline & \multirow[t]{2}{*}{$\operatorname{All}(\%)^{1}$} & \multirow{2}{*}{$\begin{array}{l}0 \\
N(\%)^{*}\end{array}$} & \multirow{2}{*}{$\begin{array}{l}1 \\
N(\%)^{*}\end{array}$} & \multirow{2}{*}{$\begin{array}{l}2 \\
N(\%)^{*}\end{array}$} & \multirow[t]{2}{*}{$P$ value $^{\mathrm{a}}$} \\
\hline & & & & & \\
\hline All (\%) & $141(100)$ & $38(27.0)$ & $70(49.6)$ & $33(23.4)$ & \\
\hline \multicolumn{6}{|l|}{ Age } \\
\hline$<50$ years & $47(33.3)$ & $8(17.0)$ & $29(61.7)$ & $10(21.3)$ & \multirow[t]{2}{*}{0.092} \\
\hline$\geq 50$ years & $94(66.7)$ & $30(31.9)$ & $41(43.6)$ & $23(24.5)$ & \\
\hline \multicolumn{6}{|l|}{ Tumour size } \\
\hline $\mathrm{T} 1$ & $38(27.0)$ & $9(23.7)$ & $17(44.7)$ & 12 (31.6) & \multirow[t]{2}{*}{0.378} \\
\hline $\mathrm{T} 2$ & $103(73.0)$ & $29(28.1)$ & $53(51.5)$ & $21(20.4)$ & \\
\hline \multicolumn{6}{|l|}{ Nodal status } \\
\hline N1 & 108 (76.6) & $26(24.1)$ & $56(51.8)$ & $26(24.1)$ & \multirow[t]{2}{*}{0.376} \\
\hline $\mathrm{N} 2$ & $33(23.4)$ & $12(36.4)$ & $14(42.4)$ & $7(21.2)$ & \\
\hline \multicolumn{6}{|l|}{ Grade } \\
\hline $\mathrm{G} 1+\mathrm{G} 2$ & $71(50.4)$ & $10(14.1)$ & $37(52.1)$ & $24(33.8)$ & \multirow[t]{2}{*}{0.000} \\
\hline G3 & $70(49.6)$ & $28(40.0)$ & $33(47.1)$ & $9(12.9)$ & \\
\hline \multicolumn{6}{|l|}{ Oestrogen receptor status } \\
\hline Positive & $97(68.8)$ & $11(11.0)$ & $58(58.0)$ & $31(31.0)$ & \multirow[t]{2}{*}{0.000} \\
\hline Negative & $44(31.2)$ & $28(63.6)$ & $14(31.8)$ & $2(4.6)$ & \\
\hline \multicolumn{6}{|c|}{ Progesterone receptor status } \\
\hline Positive & $93(66.0)$ & $10(10.7)$ & $53(57.0)$ & $30(32.3)$ & \multirow[t]{2}{*}{0.000} \\
\hline Negative & $48(34.0)$ & $28(58.3)$ & $17(35.4)$ & $3(6.3)$ & \\
\hline \multicolumn{6}{|c|}{ Cytokeratin 5/6 expression } \\
\hline Positive & $30(21.3)$ & $13(43.3)$ & $15(50.0)$ & $2(6.7)$ & \multirow[t]{2}{*}{0.015} \\
\hline Negative & $111(78.7)$ & $25(22.5)$ & $55(49.6)$ & $31(27.9)$ & \\
\hline \multicolumn{6}{|l|}{ HER2 status } \\
\hline Overexpressing & $54(38.3)$ & $19(35.2)$ & $27(50.0)$ & $8(14.8)$ & \multirow[t]{2}{*}{0.084} \\
\hline Not overexpressing & $87(61.7)$ & $19(21.8)$ & $43(49.4)$ & $25(28.7)$ & \\
\hline \multicolumn{6}{|l|}{ TOPOII $\alpha \mathrm{LI}^{\mathrm{c}}$} \\
\hline$\leq 11.9 \%$ & $71(50.4)$ & $16(22.5)$ & $37(52.1)$ & $18(25.4)$ & 0.486 \\
\hline$>11.9 \%$ & $70(49.6)$ & $22(31.4)$ & $33(47.1)$ & $15(21.4)$ & \\
\hline $\mathrm{Ki}-67 \mathrm{LI}^{\mathrm{c}}$ & & & & & \\
\hline$\leq 19.7 \%$ & $74(52.5)$ & $15(20.3)$ & $36(48.6)$ & $23(31.1)$ & 0.038 \\
\hline$>19.7 \%$ & $67(47.5)$ & $23(34.3)$ & $34(50.7)$ & $10(14.9)$ & \\
\hline $\mathrm{MVD}^{\mathrm{d}}$ & & & & & \\
\hline$\leq 210.0$ vessels $/ \mathrm{mm}^{2}$ & $96(68.1)$ & $28(29.1)$ & $47(49.0)$ & $21(21.9)$ & 0.645 \\
\hline$>210.0$ vessels $/ \mathrm{mm}^{2}$ & $45(31.9)$ & $10(22.2)$ & $23(51.1)$ & $12(26.7)$ & \\
\hline P53LI & & & & & \\
\hline$\leq 10.0 \%$ & $100(70.9)$ & $20(20.0)$ & $55(55.0)$ & $25(25.0)$ & 0.014 \\
\hline$>10.0 \%$ & $41(29.1)$ & $18(43.9)$ & $15(36.6)$ & $8(19.5)$ & \\
\hline Breast cancer immunop & types ${ }^{\mathrm{e}}$ & & & & \\
\hline LA & $42(29.8)$ & $5(11.9)$ & $19(45.2)$ & $18(42.9)$ & 0.000 \\
\hline 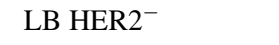 & $22(15.6)$ & $0(0.0)$ & $16(72.7)$ & $6(27.3)$ & \\
\hline${\text { LB HER } 2^{+}}^{+}$ & $33(23.4)$ & $5(15.2)$ & $21(63.6)$ & $7(21.2)$ & \\
\hline $\mathrm{HER}^{+}{ }^{+}$ & $21(14.9)$ & $14(66.7)$ & $6(28.5)$ & $1(4.8)$ & \\
\hline $\mathrm{TN}$ & $23(16.3)$ & $14(60.9)$ & $8(34.8)$ & $1(4.3)$ & \\
\hline
\end{tabular}

and TOPOII $\alpha$ LI, the cut-off point values remained at the same level as previously published (median values for both parameters) (Biesaga et al. 2011, 2012). For
MVD, we changed the cut-off point from 214.8 to 210.0 microvessels $/ \mathrm{mm}^{2}$, as at this cut-off point, the highest level of significance was observed. DFS was significantly 
Table 4 Univariate Cox proportional hazard model for disease-free survival of 171 breast cancer patients treated with adjuvant anthracyclinebased chemotherapy
$H R$ hazard ratio, $C I$ confidence interval, HER2 human epidermal growth factor receptor 2, Ki-67LI Ki-67 labelling index, TOPOII $\alpha$ LI topoisomerase II $\alpha$ labelling index, $M V D$ microvessel density, P53LI P53 labelling index, $L A$ luminal A, $L B$ luminal $\mathrm{B}, T N$ triple negative $* P$ values from log-rank test

a Median value

${ }^{\text {b }}$ Cut-off point from minimal $P$ value method

c Mean value

d Immunophenotypes indicated on the basis of ER, PgR, HER2 and $\mathrm{Ki}-67$ expression according to St. Gallen International Expert Consensus on The Primary Therapy of Early Breast Cancer 2013 (Goldhirsch et al. 2013)

\begin{tabular}{|c|c|c|c|c|}
\hline & Response $N(\%)$ & HR & $95 \% \mathrm{CI}$ & $P$ value* \\
\hline \multicolumn{5}{|l|}{ Age } \\
\hline$>50$ years & $90 / 115(78.3)$ & 1.080 & $0.534-2.189$ & 0.830 \\
\hline$\leq 50$ years & $45 / 56(80.4)$ & 1.000 & & \\
\hline \multicolumn{5}{|l|}{ Tumour size } \\
\hline $\mathrm{T} 1$ & $45 / 52(86.5)$ & 1.000 & $0.846-4.374$ & 0.109 \\
\hline $\mathrm{T} 2$ & $90 / 119(75.6)$ & 1.924 & & \\
\hline \multicolumn{5}{|l|}{ Nodal status } \\
\hline N1 & $107 / 132(81.1)$ & 1.000 & $0.783-3.214$ & 0.206 \\
\hline $\mathrm{N} 2$ & $28 / 39(71.8)$ & 1.587 & & \\
\hline \multicolumn{5}{|l|}{ Grade } \\
\hline $\mathrm{G} 1+\mathrm{G} 2$ & $81 / 92(88.0)$ & 1.000 & $1.508-6.198$ & 0.001 \\
\hline G3 & $54 / 79(68.4)$ & 3.057 & & \\
\hline \multicolumn{5}{|c|}{ Oestrogen receptor status } \\
\hline Positive & $102 / 123(82.9)$ & 1.000 & $0.262-1.021$ & 0.017 \\
\hline Negative & $33 / 48(68.8)$ & 1.932 & & \\
\hline \multicolumn{5}{|c|}{ Progesterone receptor status } \\
\hline Positive & $98 / 119(82.4)$ & 1.000 & $0.296-1.150$ & 0.045 \\
\hline Negative & $37 / 52(71.2)$ & 1.716 & & \\
\hline \multicolumn{5}{|l|}{ HER2 status } \\
\hline Overexpressing & $55 / 68(80.9)$ & 1.000 & $0.523-1.984$ & 0.750 \\
\hline Not overexpressing & $80 / 103(77.7)$ & 1.019 & & \\
\hline \multicolumn{5}{|l|}{ Cytokeratin 5/6 } \\
\hline Positive & $23 / 35(65.7)$ & 2.301 & $1.154-4.588$ & 0.021 \\
\hline Negative & $112 / 136(82.4)$ & 1.000 & & \\
\hline \multicolumn{5}{|l|}{$\mathrm{Ki}-67 \mathrm{LI}^{\mathrm{a}}$} \\
\hline$\leq 19.7 \%$ & $74 / 90(82.2)$ & 1.000 & $1.063-4.329$ & 0.270 \\
\hline$>19.7 \%$ & $61 / 81(75.3)$ & 2.196 & & \\
\hline \multicolumn{5}{|l|}{ TOPOII $\alpha \mathrm{LI}^{\mathrm{a}}$} \\
\hline$\leq 11.9 \%$ & $73 / 83(88.0)$ & 1.000 & $1.376-5.886$ & 0.003 \\
\hline$>11.9 \%$ & $62 / 88(72.6)$ & 2.846 & & \\
\hline \multicolumn{5}{|l|}{$\mathrm{MVD}^{\mathrm{b}}$} \\
\hline$>210.0$ vessels $/ \mathrm{mm}^{2}$ & $52 / 53(98.1)$ & 1.000 & $0.009-0.460$ & 0.000 \\
\hline$\leq 210.0$ vessels $/ \mathrm{mm}^{2}$ & $83 / 118(71.3)$ & 15.724 & & \\
\hline \multicolumn{5}{|l|}{ P53 LI } \\
\hline$>10.0 \%$ & $35 / 50(70.0)$ & 1.935 & $1.000-3.742$ & 0.052 \\
\hline$\leq 10 \%$ & $100 / 121(82.6)$ & 1.000 & & \\
\hline \multicolumn{5}{|l|}{ BCL-2 expression } \\
\hline Class 0 & $24 / 37(64.9)$ & 2.873 & $0.156-0.776$ & 0.005 \\
\hline Class 1 & $59 / 70(84.3)$ & 1.302 & & \\
\hline Class 2 & $29 / 33(87.9)$ & 1.000 & $0.246-2.401$ & \\
\hline \multicolumn{5}{|c|}{ Breast cancer immunophenotypes ${ }^{\mathrm{d}}$} \\
\hline LA & $41 / 50(80.8)$ & 1.000 & $0.350-2.164$ & 0.081 \\
\hline LB HER2 ${ }^{-}$ & $24 / 29(79.6)$ & 1.084 & & \\
\hline${\text { LB HER }{ }^{+}}^{+}$ & $37 / 44(84.0)$ & 1.094 & $0.386-2.410$ & \\
\hline $\mathrm{HER}^{+}{ }^{+}$ & $18 / 24(74.5)$ & 1.717 & $0.624-4.729$ & \\
\hline $\mathrm{TN}$ & $15 / 24(62.5)$ & 2.581 & $1.024-6.503$ & \\
\hline
\end{tabular}

associated with histological grade $(P=0.001)$, ER $(P=0.017)$ or $\operatorname{PgR}(P=0.045)$ status, CK5/6 expression $(P=0.021)$, TOPOII $\alpha$ LI $(P=0.003)$ and MVD
$(P=0.000)$ (Table 4). In case of P53 expression and cancer immunophenotypes, this relation was at significance border. 
Table 5 Multivariate Cox regression analysis on disease-free survival of 171 breast cancer patients

\begin{tabular}{|c|c|c|c|}
\hline & HR & $95 \% \mathrm{CI}$ & $P$ value \\
\hline \multicolumn{4}{|l|}{ Grade } \\
\hline $1+2$ & 1.000 & $0.611-4.176$ & 0.329 \\
\hline 3 & 1.610 & & \\
\hline \multicolumn{4}{|l|}{ Oestrogen receptor status } \\
\hline Positive & 1.000 & $0.580-3.792$ & 0.412 \\
\hline Negative & 1.484 & & \\
\hline \multicolumn{4}{|l|}{ Progesterone receptor status } \\
\hline Positive & 1.000 & $0.355-1.748$ & 0.560 \\
\hline Negative & 1.269 & & \\
\hline \multicolumn{4}{|l|}{ Cytokeratin 5/6 expression } \\
\hline Positive & 1.801 & $0.782-4.144$ & 0.169 \\
\hline Negative & 1.000 & & \\
\hline \multicolumn{4}{|l|}{ TOPOII $\alpha \mathrm{LI}^{\mathrm{a}}$} \\
\hline$\leq 11.9 \%$ & 1.000 & $1.202-6.303$ & 0.017 \\
\hline$>11.9 \%$ & 2.752 & & \\
\hline \multicolumn{4}{|l|}{$\mathrm{MVD}^{\mathrm{b}}$} \\
\hline$>210.0$ vessels $/ \mathrm{mm}^{2}$ & 1.000 & $0.010-0.509$ & 0.009 \\
\hline$\leq 210.0$ vessels $/ \mathrm{mm}^{2}$ & 14.352 & & \\
\hline \multicolumn{4}{|l|}{ P53LI } \\
\hline$\leq 10.0 \%$ & 1.000 & $0.536-2.679$ & 0.662 \\
\hline$>10.0 \%$ & 1.198 & & \\
\hline \multicolumn{4}{|l|}{ BCL-2 expression } \\
\hline Classes $1+2$ & 1.000 & $0.153-0.699$ & 0.004 \\
\hline Class 0 & 3.056 & & \\
\hline \multicolumn{4}{|l|}{ Breast cancer immunophenotypes $^{\mathrm{d}}$} \\
\hline $\mathrm{LA}+\mathrm{LB}\left(\mathrm{HER} 2^{-}\right.$and $\left.\mathrm{HER} 2^{+}\right)$ & 1.000 & $0.322-2.886$ & 0.947 \\
\hline $\mathrm{HER}^{+}+\mathrm{TN}$ & 1.038 & & \\
\hline
\end{tabular}

TOPOII $\alpha L I$ topoisomerase II $\alpha$ labelling index, $M V D$ microvessel density, P53LI P53 labelling index, $L A$ luminal A, $L B$ luminal B, $T N$ triple negative

a Median values

${ }^{\text {b }}$ Cut-off point from minimal $P$ value method

c Mean value

${ }^{d}$ Immunophenotypes indicated on the basis of ER, PgR, HER2 and Ki-67 expression according to St. Gallen International Expert Consensus on The Primary Therapy of Early Breast Cancer 2013 (Goldhirsch et al. 2013)

\section{Multivariate analysis}

The multivariate analysis included the variables for which in univariate analysis, significant differences or differences at significance border in DFS were seen, i.e. grade, hormone receptors status, CK5/6 expression, Ki-67LI, TOPOII $\alpha$ LI, MVD, P53LI, BCL-2 expression and breast cancer immunophenotypes. BCL-2 expression was categorized into two classes: BCL-2 negativity (class 0 ) and positivity (classes $1+2$ ). In case of breast cancer

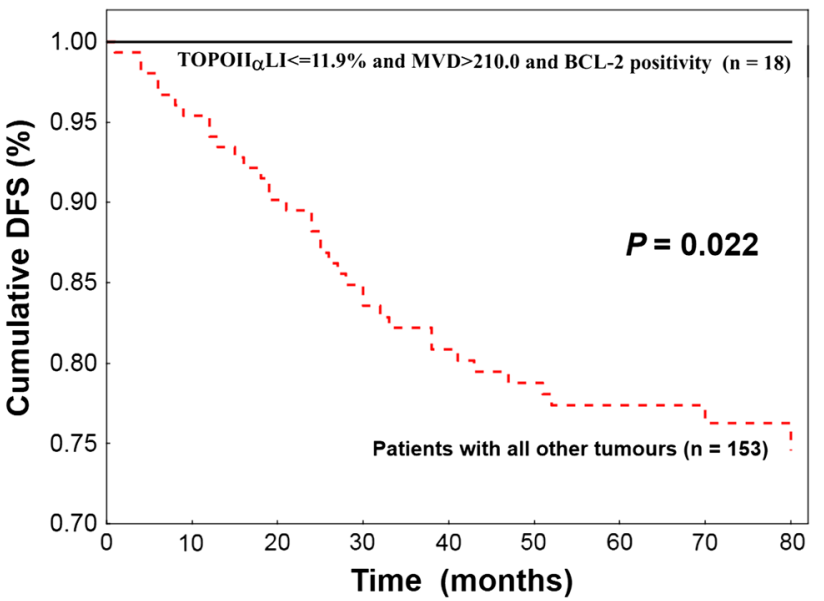

Fig. 2 Low topoisomerase II $\alpha$ expression, high microvessel density and BCL-2 positivity indicate $100 \%$ probability of 5-year diseasefree survival (DFS) of 18 patients with breast cancer. Women having tumours with other combination of these three biological features $(n=153)$ demonstrate significantly lower DFS (log-rank test)

immunophenotypes, we stratified patients into two subgroups: those with LA and LB (HER2 ${ }^{-}$and HER2 ${ }^{+}$) carcinomas and those with HER2 ${ }^{+}$or TN tumours. Multivariate analysis revealed topoisomerase II $\alpha$ expression, microvessel density and BCL-2 status as independent prognostic factors for adjuvant chemotherapy with anthracyclines (Table 5).

Based on these results, we decided to divide the analysed group into two subgroups of different prognosis: (1) women with tumours characterized by low TOPO $\alpha \mathrm{LI}$ and high MVD and BCL-2 positivity $(n=18)$ and (2) the remaining patients $(n=153)$. All 18 patients from subgroup 1 survived 80 months after treatment completion without any evidence of cancer disease, whereas DFS for women from subgroup 2 was $76.5 \%$ (Fig. 2). The difference in DFS between these subgroups was significant $(P=0.022)$.

\section{Discussion}

In the present study, we have shown, to the best of our knowledge, for the first time, $100 \%$ DFS for patients having tumours characterized by low topoisomerase II $\alpha$ expression and high microvessel density and BCL-2 positivity (all assessed by immunohistochemistry). The results suggest that these three parameters may constitute an input into the new prognostication model specially dedicated to adjuvant anthracycline-based chemotherapy of breast cancer patients. This suggestion is in agreement with other results showing that BCL-2 expression can improve prognostication of $\mathrm{BC}$ patients treated with different $\mathrm{CT}$ 
regimens. Abdel-Fatah et al. (2010), in the group of 245 patients with invasive BC treated with adjuvant ATCbased chemotherapy, found a good prognosis for patients with active or partially inactive P53 pathway (assessed by expression of BCL-2, p21, p27, hormone receptors, P53, Ki-67, EGFR, CK 5/6 and HER2 gene amplification status). In turn, Hwang et al. (2012) assessed prognostic influence of BCL-2 expression in the group of 7,230 primary BC patients in clinical stage 1,2 or 3 , of whom 4,532 received different systemic therapy. They have shown that the risk groups of cancer patients, identified by St. Gallen model or Nottingham Prognostic Index model or TNM staging, could be subdivided by addition of the BCL-2 assessment in all three models. Callagy et al. (2006) have also found that BCL-2 was the only marker from a panel of 13 proteins (HER2, c-Myc, cyclin E, CK5/6, CK17, CK8/18, ER, Ki-67, MCM-2, p27, P53 and PgR) that improved prognostication in the group of 930 breast cancer patients, some of whom were treated with adjuvant CT.

The positive prognostic significance of low TOPOII $\alpha$ expression and high MVD is in concordance with results obtained by some authors (TOPOII $\alpha$ : Fritz et al. 2005; Depowski et al. 2000; MVD: Gunel et al. 2002; Protopapa et al. 1993). The positive effect of low TOPOII $\alpha$ may be explained by hypothesis suggesting that low enzyme expression is related to less aggressive tumour phenotype, characterized by low histological grade, hormone receptors positivity, CK5/6 negativity and low proliferation rate, what was shown by us (Biesaga et al. 2011) and other authors (Fritz et al. 2005; Durbecq et al. 2004; Depowski et al. 2000). In turn, the positive influence of high MVD on ATC treatment outcome may be related to enhancement of production of reactive oxygen species under ATC or increased drug access to tumour cells in well-vascularized tumours. All these suggestions were carefully discussed in our earlier publications (Biesaga et al. 2011, 2012); therefore, in the present paper, we would like to focus on prognostic potential of BCL-2 expression.

We have shown that BCL-2 expression is independent prognostic factor for adjuvant chemotherapy with ATC, what is in agreement with results of a few other reports in which analysis of subgroups of patients treated with ATC in adjuvant settings was provided (see Table 1). Some of these data were summarized in meta-analysis performed by Callagy et al. (2008), who included seventeen papers published since 2006, reporting data of almost 6,000 patients with $\mathrm{BC}$, regardless of the treatment type. This meta-analysis supports that BCL-2 overexpression indicates good prognosis. This effect was independent of lymph node status, tumour size or grade as well as a range of other biological variables. However, another meta-analysis from 2013, in which 23 studies involving almost 2,500 BC patients, showed that negative BCL-2 expression was associated with pathological complete response in women treated with ATC-based neoadjuvant chemotherapy (Yang et al. 2013). We mentioned about the possible causes of these contrary results in Introduction section.

The reasons of positive prognostic potential of BCL-2 overexpression are not fully understood. It is well known that this protein has oncogenic function related to inhibition of apoptosis and hence tumour progression and metastatic potential (Short and Johnstone 2012). However, in some types of tumour, BCL-2 seems to play both oncogenic and suppressive role. It is postulated that the dominance of one of these functions over another may depend on the cell type and physiology and that suppressive effect dominates in solid epithelial tumours including breast cancer (Zinkel et al. 2006). BCL-2 suppressive function may be a consequence of its non-apoptotic functions, particularly its ability to control cell cycle machinery, what was supported by cell line studies in which relation between BCL-2 expression and G0 prolongation and delay of G1-S transition was shown (Zinkel et al. 2006; Pietenpol et al. 1994).

Positive prognostic significance of BCL-2 overexpression may be explained by its influence on $\mathrm{BC}$ cell chemosensitivity. Del Bufalo et al. (2002) have shown that human BC cell lines overexpressing BCL-2 displayed an increased sensitivity to drugs known to induce multidrug resistance phenomenon (MDR) such as doxorubicin, vincristine, vinblastine and actinomycin, whereas they show increased resistance to drugs not related to the MDR (cisplatin and bischloroethylnitrosourea). The enhanced sensitivity to doxorubicin was associated with an increased drug accumulation and its decreased efflux as well as with reduction of the adenosine triphosphate level and kinase $\mathrm{C}$ activity, both of which participate in the regulation of MDR. In earlier studies, the above-referred authors have demonstrated that BCL-2 overexpression was related to inhibition of mitochondrial metabolism and reduction of oxygen uptake and ${ }^{14} \mathrm{CO}_{2}$ production (Biroccio et al. 1999).

The positive prognostic power of BCL-2 overexpression may be also related to its correlation with other favourable prognostic markers such as lower tumour grade, oestrogen and progesterone positivity, cytokeratin negativity, lack of HER2 overexpression, which was shown in our study and is in agreement with other authors (van Slooten et al. 1996; Mottolese et al. 2000; Yang et al. 2003; Lee et al. 2007; Kim et al. 2010). We have also found the higher percentage of BCL-2-positive tumours among luminal A and B cancer immunophenotypes as compared with $\mathrm{HER}^{+}$and TN immunophenotypes. Therefore, BCL-2 expression may also reflect lower degree of tumour differentiation.

In the presented analysis, based on BCL-2 expression, we could stratify patients with triple negative tumours into two subgroups with different prognosis. TN breast cancer patients with BCL-2 overexpression had significantly 
higher DFS than those with BCL-2 negativity. These results should be, however, interpreted with care, because of the small number of patients in each subgroup (7 and 13, respectively). Nonetheless, presented results are partly in agreement with those obtained by other authors. AbdelFatah et al. (2013) in the large cohort of 635 patients with early advanced TN breast cancers have found that BCL-2 negativity was associated with approximately twice the risk of death and recurrence in patients who did not receive CT or were treated with CMF. In turn, they have shown longer survivals in BCL-2-negative TN BC patients exposed to anthracyclines than in those who did not receive chemotherapy or were treated with CMF. Relatively high DFS in BCL-2-positive TN tumours obtained by us could also confirm results of earlier reports, showing that a subset of TN breast cancer patients responded to standard chemotherapy and had survival rate similar to women with other breast cancer immunophenotypes (Liedtke et al. 2008). However, Tawfik et al. (2012), contrary to us, have demonstrated association between BCL-2 positivity and poorer survival only among non-TN breast cancer patients, whereas in the group of TN breast cancer patients, BCL-2 status had no influence on treatment outcome. These discrepancies may be explained by heterogeneity of TN subtype, which represents distinct molecular subgroups that differentially respond to chemotherapy. Lehmann et al. (2011), analysing gene expression profiles, have identified six distinct molecular subtypes of TNBC including two basal like, an immunomodulatory, a mesenchymal, a mesenchymal stem-like and a luminal androgen receptor subtype. In the next report of this team, in the group of 130 patients with TN BC who received neoadjuvant chemotherapy containing sequential taxane and ATC chemotherapy, significant relation between TN BC subtypes and pathological complete response status was found (Masuda et al. 2013). Thus, in the light of our and some other author's results, we postulate that BCL-2 expression may be one of the surrogate markers allowing distinguishing TN BC subtypes with different sensitivity to ATC; however, this supposition requires confirmation in further studies.

In conclusion, in the present study, we have shown, to the best of our knowledge for the first time, that by combination of three parameters: BCL-2 positivity, low topoisomerase II $\alpha$ expression and high microvessel density, it is possible to identify subgroups of BC patients with very good prognosis after adjuvant anthracycline-based chemotherapy. All these three parameters were assessed by immunohistochemistry, which is an inexpensive and routine method, widely used in pathology and radiobiology departments. Therefore, assessment of these proteins is easy for implementation in daily clinical practise. However, the presented results should be confirmed in larger, prospective clinical trials.
Acknowledgments This work was supported by the Polish Ministry of Education and Science, grant number N401 173 31/3808.

Conflict of interest The authors declare that they have no known conflicts of interest.

Open Access This article is distributed under the terms of the Creative Commons Attribution License which permits any use, distribution, and reproduction in any medium, provided the original author(s) and the source are credited.

\section{References}

Abdel-Fatah TM, Powe DG, Agboola J, Adamowicz-Brice M, Blamey RW, Lopez-Garcia MA, Green AR, Reis-Filho JS, Ellis IO (2010) The biological, clinical and prognostic implications of p53 transcriptional pathways in breast cancers. J Pathol 220(4):419-434. doi:10.1002/path.2663

Abdel-Fatah TM, Perry C, Dickinson P, Ball G, Moseley P, Madhusudan S, Ellis IO, Chan SY (2013) Bcl2 is an independent prognostic marker of triple negative breast cancer (TNBC) and predicts response to anthracycline combination (ATC) chemotherapy (CT) in adjuvant and neoadjuvant settings. Ann Oncol 24(11):28012807. doi:10.1093/annonc/mdt277

Biesaga B, Niemiec J, Ziobro M, Wysocka J, Kruczak A (2011) Prognostic potential of topoisomerase II $\alpha$ and HER2 in a retrospective analysis of early advanced breast cancer patients treated with adjuvant anthracycline chemotherapy. Breast 20(4):338-350. doi:10.1016/j.breast.2011.03.002

Biesaga B, Niemiec J, Ziobro M (2012) Microvessel density and status of p53 protein as potential prognostic factors for adjuvant anthracycline chemotherapy in retrospective analysis of early breast cancer patients group. Pathol Oncol Res 18(4):949-960. doi:10.1007/s12253-012-9525-9

Biroccio A, Del Bufalo D, Fanciulli M, Bruno T, Zupi G, Floridi A (1999) bcl-2 inhibits mitochondrial metabolism and lonidamine-induced apoptosis in adriamycin-resistant MCF7 cells. Int J Cancer 82(1):125-130. doi:10.1002/ (SICI) 1097-0215(19990702)8

Callagy GM, Pharoah PD, Pinder SE, Hsu FD, Nielsen TO, Ragaz J, Ellis IO, Huntsman D, Caldas C (2006) Bcl-2 is a prognostic marker in breast cancer independently of the Nottingham Prognostic Index. Clin Cancer Res 12(8):2468-2475. doi:10.1158/1078-0432.CCR-05-2719

Callagy GM, Webber MJ, Pharoah PD, Caldas C (2008) Metaanalysis confirms BCL2 is an independent prognostic marker in breast cancer. BMC Cancer 29(8):153. doi:10.1186/14712407-8-153

Del Bufalo D, Biroccio A, Trisciuoglio D, Bruno T, Floridi A, Aquino A, Zupi G (2002) Bcl-2 has differing effects on the sensitivity of breast cancer cells depending on the antineoplastic drug used. Eur J Cancer 38(18):2455-2462. doi:10.106/ S0959-8049(02)00391-X

Depowski PL, Rosenthal SI, Brien TP, Stylos S, Johnson RL, Ross JS (2000) Topoisomerase II alpha expression in breast cancer: correlation with outcome variables. Mod Pathol 13(5):542-547

Dumontet C, Krajewska M, Treilleux I, Mackey JR, Martin M, Rupin M, Lafanechère L, Reed JC (2010) BCIRG 001 molecular analysis: prognostic factors in node-positive breast cancer patients receiving adjuvant chemotherapy. Clin Cancer Res 16(15):39883997. doi:10.1158/1078-0432.CCR-10-0079

Durbecq V, Paesmans M, Cardoso F, Desmedt C, Di Leo A, Chan S et al (2004) Topoisomerase-II alpha expression as a predictive 
marker in a population of advanced breast cancer patients randomly treated either with single-agent doxorubicin or singleagent docetaxel. Mol Cancer Ther 3(10):1207-1214

Early Breast Cancer Trialists' Collaborative Group (EBCTCG), Peto R, Davies C, Godwin J, Gray R, Pan HC, Clarke M, Cutter D, Darby S, McGale P, Taylor C, Wang YC, Bergh J, Di Leo A, Albain K, Swain S, Piccart M, Pritchard K (2012) Comparisons between different polychemotherapy regimens for early breast cancer: meta-analyses of long-term outcome among 100, 000 women in 123 randomised trials. Lancet 379(9814):432-444. doi:10.1016/S0140-6736(11)61625-5

Fritz P, Cabrera CM, Dippon J, Gerteis A, Simon W, Aulitzky WE, van der Kuip H (2005) c-erbB2 and topoisomerase II alpha protein expression independently predict poor survival in primary human breast cancer: a retrospective study. Breast Cancer Res 7(3):R374-R384. doi:10.1186/bcr1012

Goldhirsch A, Winer EP, Coates AS, Gelber RD, Piccart-Gebhart M, Thürlimann B, Senn HJ (2013) Panel members personalizing the treatment of women with early breast cancer: highlights of the St Gallen international expert consensus on the primary therapy of early breast cancer. Ann Oncol 24(9):2206-2223. doi:10.1093/a nnonc/mdt303

Gunel N, Akcali Z, Coskun U, Akyol G, Yamac D, Yenidünya S (2002) Prognostic importance of tumor angiogenesis in breast carcinoma with adjuvant chemotherapy. Pathol Res Pract 198(1):7-12. doi:10.1078/0344-0338-00177

Hwang KT, Woo JW, Shin HC, Kim HS, Ahn SK, Moon HG, Han W, Park IA, Noh DY (2012) Prognostic influence of BCL2 expression in breast cancer. Int J Cancer 131(7):E1109-E1119. doi:10.1002/ijc.27539

Kim K, Chie EK, Han W, Noh DY, Park IA, Oh DY, Im SA, Kim TY, Bang YJ, Ha SW (2010) Prognostic value of p53 and bcl-2 expression in patients treated with breast conservative therapy. $\mathbf{J}$ Korean Med Sci 25(2):235-239. doi:10.3346/jkms.2010.25.2.235

Kröger N, Milde-Langosch K, Riethdorf S, Schmoor C, Schumacher M, Zander AR, Löning T (2006) Prognostic and predictive effects of immunohistochemical factors in high-risk primary breast cancer patients. Clin Cancer Res 12(1):159-168. doi:10.1158/1078-0432

Lee KH, Im SA, Oh DY, Lee SH, Chie EK, Han W, Kim DW, Kim TY, Park IA, Noh DY, Heo DS, Ha SW, Bang YJ (2007) Prognostic significance of bcl-2 expression in stage III breast cancer patients who had received doxorubicin and cyclophosphamide followed by paclitaxel as adjuvant chemotherapy. BMC Cancer 12(7):63. doi:10.1186/1471-2407-7-63

Lehmann BD, Bauer JA, Chen X, Sanders ME, Chakravarthy AB, Shyr Y, Pietenpol JA (2011) Identification of human triplenegative breast cancer subtypes and preclinical models for selection of targeted therapies. J Clin Invest 21(7):2750-2767. doi:10.1172/JCI45014

Liedtke C, Mazouni C, Hess KR, André F, Tordai A, Mejia JA, Symmans WF, Gonzalez-Angulo AM, Hennessy B, Green M, Cristofanilli M, Hortobagyi GN, Pusztai L (2008) Response to neoadjuvant therapy and long-term survival in patients with triple-negative breast cancer. J Clin Oncol 26(8):1275-1281. doi:10 $.1200 / J C O .2007 .14 .4147$
Malamou-Mitsi V, Gogas H, Dafni U et al (2006) Evaluation of the prognostic and predictive value of p53 and $\mathrm{Bcl}-2$ in breast cancer patients participating in a randomized study with dose-dense sequential adjuvant chemotherapy. Ann Oncol 17(10):15041511. doi:10.1093/annonc/mdl147

Masuda H, Baggerly KA, Wang Y, Zhang Y, Gonzalez-Angulo AM, Meric-Bernstam F, Valero V, Lehmann BD, Pietenpol JA, Hortobagyi GN, Symmans WF, Ueno NT (2013) Differential response to neoadjuvant chemotherapy among 7 triple-negative breast cancer molecular subtypes. Clin Cancer Res 19(19):5533-5540. doi:10.1158/1078-0432.CCR-13-0799

Mottolese M, Benevolo M, Del Monte G, Buglioni S, Papaldo P, Nisticò C, Di Filippo F, Vasselli S, Vici P, Botti C (2000) Role of P53 and BCL-2 in high-risk breast cancer patients treated with adjuvant anthracycline-based chemotherapy. J Cancer Res Clin Oncol 126(12):722-729

Perillo B, Sasso A, Abbondanza C, Palumbo G (2000) 17beta-estradiol inhibits apoptosis in MCF-7 cells, inducing bcl-2 expression via two estrogen-responsive elements present in the coding sequence. Mol Cell Biol 20(8):2890-2901

Pietenpol JA, Papadopoulos N, Markowitz S, Willson JK, Kinzler KW, Vogelstein B (1994) Paradoxical inhibition of solid tumor cell growth by bcl2. Cancer Res 54(14):3714-3717

Protopapa E, Delides GS, Révész L (1993) Vascular density and the response of breast carcinomas to mastectomy and adjuvant chemotherapy. Eur J Cancer 29A(10):1391-1393

Short J, Johnstone RW (2012) Oncogenes in cell survival and cell death. Cold Spring Harb Perspect Biol 4(12). doi:10.1101/cshperspect.a009829

Tawfik K, Kimler BF, Davis MK, Fan F, Tawfik O (2012) Prognostic significance of Bcl-2 in invasive mammary carcinomas: a comparative clinicopathologic study between "triple-negative" and non-"triple-negative" tumors. Hum Pathol 43(1):23-30. doi:10.1016/j.humpath.2011.04.011

Treré D, Montanaro L, Ceccarelli C, Barbieri S, Cavrini G, Santini D, Taffurelli M, Derenzini M (2007) Prognostic relevance of a novel semiquantitative classification of Bcl2 immunohistochemical expression in human infiltrating ductal carcinomas of the breast. Ann Oncol 18(6):1004-1014. doi:10.1093/annonc/mdm074

van Slooten HJ, Clahsen PC, van Dierendonck JH, Duval C, Pallud C, Mandard AM, Delobelle-Deroide A, van de Velde CJ, van de Vijver MJ (1996) Expression of Bcl-2 in node-negative breast cancer is associated with various prognostic factors, but does not predict response to one course of perioperative chemotherapy. $\mathrm{Br}$ J Cancer 74(1):78-85

Yang Q, Sakurai T, Yoshimura G, Suzuma T, Umemura T, Nakamura M, Nakamura Y, Mori I, Kakudo K (2003) Prognostic value of $\mathrm{Bcl}-2$ in invasive breast cancer receiving chemotherapy and endocrine therapy. Oncol Rep 10:121-125. doi:10.3892/or.10.1.121

Yang D, Chen MB, Wang LQ, Yang L, Liu CY, Lu PH (2013) Bcl-2 expression predicts sensitivity to chemotherapy in breast cancer: a systematic review and meta-analysis. J Exp Clin Cancer Res 32:105. doi:10.1186/1756-9966-32-105

Zinkel S, Gross A, Yang E (2006) BCL2 family in DNA damage and cell cycle control. Cell Death Differ 13(8):1351-1359. doi:10.10 38/sj.cdd. 4401987 